\title{
ANALISIS KEBUTUHAN KAPASITAS PRODUKSI DENGAN MENGGUNAKAN METODE ROUGH CUT CAPACITY PLANNING DI PT WIJAYA KARYA BETON
}

\author{
Muhammad Zakaria*, Syukriah dan Rika Ayu Selvia \\ Jurusan Teknik Industri, Fakultas Teknik, Universitas Malikussaleh, Aceh, Indonesia \\ *Corresponding Author: irmuhammad@unimal.ac.id
}

\begin{abstract}
Abstrak - PT. Wijaya Karya Beton merupakan salah satu perusahaan yang bergerak dalam industri pembuatan tiang beton yang berlokasi di jalan Medan - Binjai Km 15,5 Desa Sei Semayang Kecamatan Sunggal, Kabupaten Deli Serdang. Perusahaan ini berproduksi bersadasarkan pesanan (make to order). Dimana permintaan yang tinggi akan menjadi keuntungan bagi perusahaan tetapi akan menjadi kerugian bagi perusahaan apabila tidak dapat memenuhi pesanan tepat waktu. Berdasarkan data masa lalu PT. Wijaya Karya Beton mengalami permintaan yang berfluktuatif dari bulan Januari- Desember 2019 namun tidak mempertimbangkan sumberdaya kapasitas produksi yang tersedia sehingga terjadi keterlambatan dalam menyelesaikan produk. Penelitian ini bertujuan untuk mengetahui kebutuhan kapasitas produksi dengan metode rough cut capacity planning serta menggunakan perhitungan peramalan sebagai acuan permintaan konsumen dimasa yang akan datang. Berdasarkan hasil laporan RCCP kekurangan kapasitas terjadi pada work centre III, V, VI, VII. Pada work centre III kekurangan kapasitas sebesar 114 jam dan pada work centre V kekurangan kapasitas sebesar 116 jam, langkah yang dilakukan untuk mengatasi kekurangan kapasitas dengan melakukan penyesuaian (readjustment) kapasitas dengan memindahkan beban kerja ke periode yang mengalami kelebihan kapasitas. Pada work centre VI kekurangan kapasitas sebesar 29140 jam dan pada work centre VII kekurangan kapasitas sebesar 2435 jam, langkah yang dilakukan untuk mengatasi kekurangan kapasitas dengan menambahkan jam kerja lembur disetiap bulannya. Setelah dilakukan penyesuain (readjustment) dan penambahan jam kerja lembur maka kapasitas untuk setiap work centre dapat terpenuhi.
\end{abstract}

Kata Kunci: Kapasitas, Peramalan, Rough Cut Capacity Planning

\section{Pendahuluan}

Perkembangan dunia bisnis dan industri sekarang ini memiliki pertumbuhan yang sangat pesat. Saat ini banyak bermunculan usaha khususnya dalam bidang manufaktur. Tingginya pertumbuhan tersebut akan menimbulkan persaingan antara satu perusahaan dengan perusahaan lainnya untuk menjadi yang terdepan. Perusahaan dituntut untuk menghasilkan produk yang bermutu dan memenuhi kepuasan konsumen dimana itu menjadi penentu posisi perusahaan dalam persaingan bisnis. Kualitas produk suatu perusahaan harus sesuai dengan yang diharapkan oleh konsumen. Dengan demikian, suatu perusahaan dituntut untuk memanfaatkan segala fasilitas yang dimiliki untuk memberikan kepuasaan yang maksimal kepada konsumen.

Pemenuhan permintaan konsumen dapat terealisasi seluruhnya tergantung dari perencanaan jadwal induk produksi jika didukung oleh kapasitas produksi. Jadwal induk produksi dapat terealisasi dengan baik apabila permintaan konsumen bersifat konstan tetapi tidak jarang permintaan mengalami fluktuasi yang cenderung meningkat dan tidak stabil. Permintaan yang berfluktuasi mengakibatkan kesulitan pada perusahaan karena sumberdaya yang dimilki oleh perusahaan relatif konstan seperti kapasitas produksi dan tenaga operator.

PT. Wijaya Karya Beton adalah perusahaan yang bergerak dalam industri pembuatan tiang beton yang berlokasi di jalan Medan - Binjai Km 15,5 Desa Sei Semayang Kecamatan Sunggal, Kabupaten Deli Serdang. Produk yang dihasilkan PT. Wijaya Karya Beton adalah PC Piles (TP), PC Piles (TL), Railway Concrete Products (RY), Bridge Concrete Products (BR), dan Retaining Wall Concrete Products (RT). PT. Wijaya Karya Beton berproduksi berdasarkan pesanan (make to order).

Selama tahun 2019, PT. Wijaya Karya Beton mengalami ketidakmampuan dalam memenuhi permintan konsumen untuk produk tiang pancang yaitu pada bulan Januari sebanyak 412 unit, februari sebanyak 325 unit, maret sebanyak 226 unit, april sebanyak 261 
unit, mei sebanyak 255 unit, juni sebanyak 65 unit, juli sebanyak 277 unit, agustus sebanyak 332 unit. September sebanyak 354 unit, oktober sebanyak 17 unit, november sebanyak 169 unit, desember sebanyak 56 unit. Ketidakmampuan tersebut disebabkan oleh fluktuasi permintaan pada produk tiang pancang yang menyebabkan kesulitan pada perusahaan untuk menentukan kapasitas optimal.

Tiang pancang ( $P C$ piles) merupakan produk yang memiliki jumlah permintaan paling tinggi dibandingkan dengan produk lainnya. Untuk membuat produk tiang pancang ada 7 unit yang harus dilalui yaitu perakitan, penulangan, pengecoran, penekanan, pemutaran cetakan, perawatan uap dan pengeluaran produk dari cetakan. Perusahaan yang memproduksi berdasarkan pesanan, permintaan yang tinggi akan produk menjadi keuntungan bagi perusahaan akan tetapi menjadi kerugian bagi perusahaan jika tidak dapat memenuhi pesanan tepat waktu dengan jumlah yang banyak. Selama ini perusahaan menerima pesanan konsumen namun tidak mempertimbangkan sumberdaya kapasitas produksi yang tersedia. Permintaan yang melebihi kapasitas akan membuat produk yang dibuat tidak selesai tepat waktu. Karena itu perlu dilakukan perhitungan kapasitas untuk memenuhi pesanan yang berfluktuatif.

Oleh karena itu PT. Wijaya Karya Beton perlu membuat jadwal induk produksi sebagai dasar penentuan jadwal proses operasi dan jadwal alokasi sumberdaya untuk mendukung penyelesaian pemesanan tepat waktu. Dengan dibuatnya jadwal induk produksi, perusahaan dapat melakukan kegiatan produksi dengan terencana dan terkendali sehingga penyelesaian produk tepat waktu dengan jumlah yang banyak.

Adapun tujuan yang ingin dicapai dalam penelitian ini adalah untuk mengetahui kebutuhan kapasitas produksi pada setiap work centre dengan rough cut capacity planning di PT. Wijaya Karya Beton.

\section{Tinjauan Pustaka}

Pere Kapasitas adalah kemampuan pembatas dari unit produksi untuk berproduksi dalam waktu tertentu dan biasanya dinyatakan dalam bentuk keluaran (output) per satuan waktu. Tetapi kapsitas adalah konsep yang kabur, karena harus dihubungkan dengan sejauh mana suatu peralatan digunakan. Sebagai contoh, bisa saja ditetapkan sebagai kebijikan untuk bekerja karya 5 hari seminggu, satu shift dalam sehari, dan produksinya 1000 satuan per minggu. Dengan dasar ini kita dapat mengatakan bahwa kapasitas normal adalah 1000 satuan output per minggu. Tetapi batas ini dapat ditingkatkan dengan kerja lembur sehingga batas kapasitas dengan kerja lembur menjadi 1150 satuan. Dengan menambah shift kedua, kapasitas dapat ditingkatkan lebih lanjut menjadi 1800 satuan perminggu. (S.Buffa, 1983).

\section{Perhitungan Waktu Baku}

Waktu baku adalah waktu yang sebenarnya digunakan operator untuk memproduksi satu unit dari data jenis produk. Waktu baku untuk setiap bagian harus dinyatakan termasuk toleransi untuk beristirahat mengatasi kelelahan atau untuk faktor-faktor yang tidak dapat dihindarikan. Dengan demikian waktu baku tersebut dapat diperoleh dengan mengaplikasikan rumus berikut (Nurmianto, 2008):

$$
\begin{aligned}
& \text { W }=\text { Ws } x \text { Rf } \\
& \text { Dimana: } \\
& \text { Wn }=\text { Waktu no............... Pers (2.1) } \\
& \text { Ws }=\text { Wakyu siklus rata-rata } \\
& \mathrm{Rf}=\text { Rating factor } \\
& \text { Wb }=\text { Wn } \times \frac{100 \%}{(100 \%-A l l o w a n c e)} \ldots . . . . . \text { Pers (2.2) } \\
& \text { Dimana: } \\
& \text { Wb }=\text { Waktu baku }
\end{aligned}
$$

\section{Peramalan}

Peramalan merupakan suatu kegiatan memperkirakan atau memprediksi kejadian dimasa yang akan datang tentunya dengan bantuan penyusunan rencana terlebih dahulu, dimana rencana ini dibuat berdasarkan kapasitas dan kemampuan permintaan/produksi yang telah dilakukan di perusahaan. Dalam kegiatan produksi, peramalan dilakukan untuk menentukan jumlah permintaan, dimana hal ini sangat sulit untuk diperkirakan secara tepat. Peramalan yang dibuat diupayakan agar dapat meminimumkan pengaruh ketidakpastian ini terhadap sebuah perusahaan (Sofyan, 2013).

\section{POM Quantitatif Method for Windows}

Program POM adalah sebuah program komputer yang digunakan untuk memecahkan masalah dalam bidang produksi dan operasi yang bersifat kuantitatif. Tampilan grafis yang menarik dan kemudahan pengoperasian menjadikan POM for windows sebagai alternatif aplikasi guna membantu pengambilan keputusan seperti misalnya menentukan kombinasi produksi yang sesuai agar memperoleh keuntungan lebih besar. Menentukan pembelian barang agar biaya perawatan atau penyimpanan seminimal mungkin, menentukan penugasan karyawan terhadap sesuatu pekerjaan agar dicapai hasil yang maksimal.

QM adalah kepanjangan dari Quantitatif Method yang merupakan perangkat lunak dan menyertai buku-buku teks seputaran manajemen operasi. QM for windows merupakan gabungan dari program terdahulu DS dan POM for window jadi dibandingkan dengan program POM for window modul-modul yang tersedia pada QM for windows lebih banyak, namun ada modul-modul yang hanya tersedia pada program POM for windows, atau hanya tersedia di program DS for windows dan tidak tersedia di QM for windows (Saebiah, 2018).

\section{Perencanaan Kapasitas Produksi}


Dalam jangka pendek perencanaan kapasitas digunakan untuk pengendalian produksi, yaitu untuk melihat apakah pelaksanaan produksi telah sesuai dengan rencana yang telah ditetapkan, Perencanaan kapasitas jangka pendek ini dilakukan dalam jangka waktu harian sampai dengan satu bulan ke depan (Kusuma, 2004).

\section{Penyusunan Jadwal Induk Produksi}

Master production schedule atau disebut juga dengan jadwal induk produksi merupakan pernyataan produk akhir (end item) yang akan diproduksi dalam bentuk jumlah dan waktu proses produksi. Jadwal induk produksi merupakan disagregasi dan implementasi perencanaan produksi (agregat) (Ginting, 2007).

Jadwal induk produksi (JIP) adalah pernyataan produk akhir (end item) apa saja yang akan diproduksi dalam bentuk jumlah dan waktu (kapan). Jadwal induk produksi merupakan disagregasi dan implementasi dari produk (agregat).

Jadwal induk produksi pada dasarnya merupakan suatu pernyataan tentang produk akhir dari suatu perusahaan industri manufaktur yang merencanakan memproduksi output berkaitan dengan kuantitas dan periode waktu (Gaspersz, 2004). Penjadwalan induk produksi pada dasarnya berkaitan dengan aktifitas melakukan empat fungsi utama adalah sebagai berikut:

1. Menyediakan atau memberikan input utama kepada sistem perencanaan kebutuhan material dan kapasitas material (material and capacity requirement)

2. Menjadwalkan pesanan-pesanan produksi dan pembelian (production and purchase orders) untuk item-item MPS.

3. Memberikan landasan untuk penentuan kebutuhan sumber daya dan kapasitas.

4. Memberikan basis pembuatan janji tentang penyerahan produk kepada pelanggan.

\section{Rough Cut Capacity Planning}

Rough Cut Capacity Planning (RCCP) dapat didefinisikan sebagai proses konversi dan rencana produksi atau MPS ke dalam kebutuhan kapasitas yang berkaitan dengan sumber-sumber daya kritis, seperti tenaga kerja, mesin dan peralatan, kapasitas gudang, kapabilitas pemasok material. RCCP ditampilkan dalam suatu diagram yang dikenal sebagai Load Profile untuk menggambarkan kapasitas yang dibutuhkan dengan kapasitas yang tersedia (Gaspersz, 2004).

Pada dasarnya terdapat empat langkah yang diperlukan untuk melaksanakan RCCP, yaitu:

1. Memperoleh informasi tentang rencana produksi dari MPS.

2. Memperoleh informasi tentang struktur dan waktu tunggu.

3. Menentukan bill of resources.

4. Menghitung sumber daya spesifik dan membuat laporan RCCP.
Rough Cut Capacity Planning menghitung kebutuhan kapasitas secara kasar dan membandingkannya dengan kapasitas tersedia. Perhitungan secara kasar terlihat dalam dua hal yang menjadi karakteristik RCCP yaitu:

1. Kebutahan kapasitas masih didasarkan pada kelompok produk, bukan produk per produk.

2. Tidak memperhitungkan jumlah persediaan yang telah ada.

Capacity requirement $=\mathrm{a}+(\mathrm{b} \times \mathrm{c})$ Pers (2.3)

Keterangan:

$\mathrm{a}=$ waktu setup (jam)

$\mathrm{b}=$ jumlah permintaan hasil peramalan (unit)

$c=$ waktu operasi (jam/unit)

Capacity available $=\mathrm{d} \times \mathrm{e} \times \mathrm{f}$ Pers (2.4)

Keterangan:

$\mathrm{d}=$ jumlah hari kerja/ bulan (hari)

e = jumlah jam kerja/hari (jam)

$f=$ jumlah mesin produksi yang tersedia (unit)

Apabila pada salah satu atau beberapa stasiun kerja dalam bulan tertentu ditemui keadaan bahwa kebutuhan kapasitas lebih besar dari kapasitas yang tersedia maka beberapa alaternatif keputusan perlu dianalisis sebagai berikut (Simulingga, 2009):

1. Alternatif 1

Rencana produksi agregat pada bulan tersebut dikoreksi yaitu diturunkan sampai kapada jumlah realistik ditinjau dari ketersediaan kapasitas. Resiko terhadap alternative ini perlu dikritis karena mengoreksi jumlah produk yang dihasilkan akan menurun pangsa pasar.

2. Alternatif 2

Melalukan penyesuaian (re-adjustment) jumlah unit produk kelompok tertentu agar time bucket misalnya sebagaian dipindahkan ke periode lebih awal atau ke periode yang dibelakangnya.

3. Alternatif 3

Melakukan penambahan kapasitas stasiun kerja dimana defisit terjadi mislanya penambahan jumlah mesin terkait dan lain-lain.

Keputusan yang diambil haruslah berdasarkan hasil analisis trade-off yang mendalam dari ketiga alternative tersebut dengan mempertimbangkan tidak hanya faktor finansial tetapi juga faktor teknis dan faktor sosial yang terkait dengan kepentingan para karyawan, pemilik modal, dan tidak terkecuali kepentingan pelanggan.

\section{Metodelogi Penelitian}

Adapun skema yang dilakukan dalam melakukan penelitian yaitu sebagai berikut: (lihat Gambar 1): 


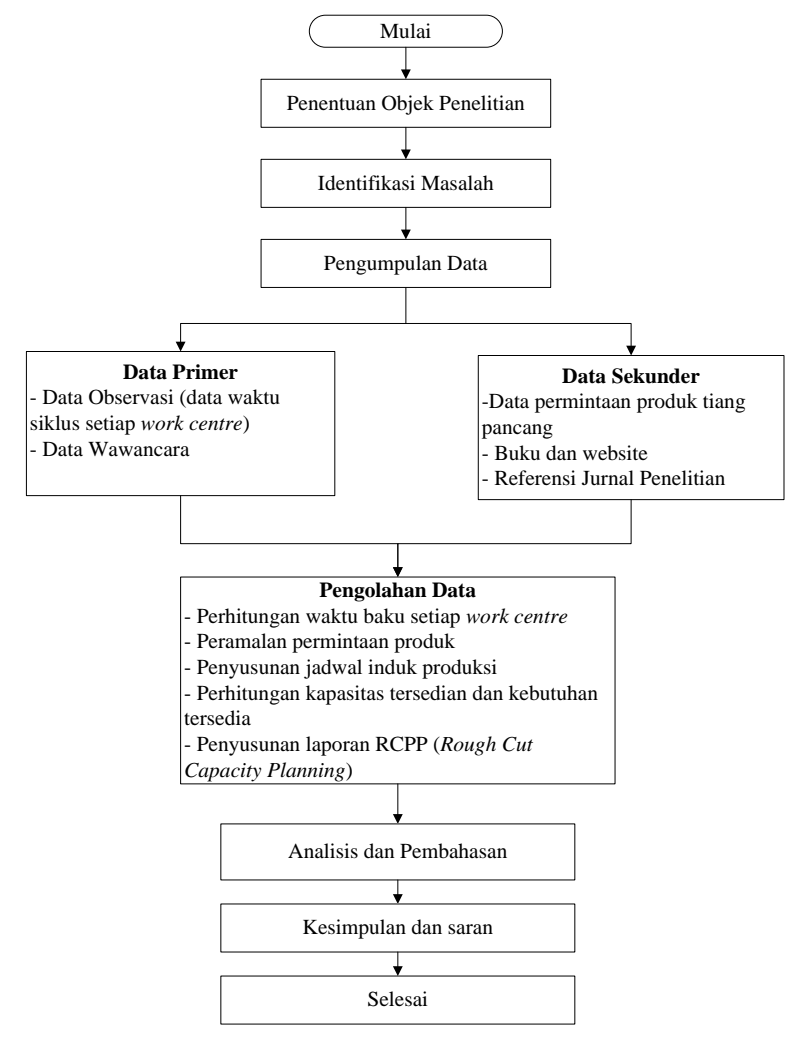

Gambar 1. Skema Metodelogi Penelitian

\section{Hasil dan Pembahasan}

\section{Pengumpulan Data}

Untuk menyelesaikan permasalahan kapasitas produksi yang terjadi di PT. Wijaya Karya Beton dengan menggunakan metode rough cut ca[acity planning. Dalam penelitian ini, pengumpulan data dilakukan melalui 6 tahap yaitu:

Data permintaan tiang pancang dari Januari 2019 desember 2019 dapat dilihat pada tabel 1 berikut ini:

Tabel 1. Data Permintaan Tiang Pancang Tahun 2019

\begin{tabular}{|c|c|c|}
\hline No & Bulan & Permintaan \\
\hline 1 & Januari & 3248 \\
\hline 2 & Februari & 4306 \\
\hline 3 & Maret & 3519 \\
\hline 4 & April & 2999 \\
\hline 5 & Mei & 3920 \\
\hline 6 & Juni & 2593 \\
\hline 7 & Juli & 3662 \\
\hline 8 & Agustus & 2930 \\
\hline 9 & September & 4616 \\
\hline 10 & Oktober & 3961 \\
\hline 11 & November & 3160 \\
\hline 12 & Desember & 3575 \\
\hline
\end{tabular}

Data jumlah hari kerja PT.Wijaya Karya Beton dari bulan Januari 2019 - Desember 2019 dapat dilihat pada tabel 2 berikut ini:
Tabel 2. Data Jumlah Hari Kerja

\begin{tabular}{|c|c|c|}
\hline No & Bulan & Hari \\
\hline 1 & Januari & 16 \\
\hline 2 & Februari & 19 \\
\hline 3 & Maret & 19 \\
\hline 4 & April & 20 \\
\hline 5 & Mei & 28 \\
\hline 6 & Juni & 13 \\
\hline 7 & Juli & 20 \\
\hline 8 & Agustus & 20 \\
\hline 9 & September & 20 \\
\hline 10 & Oktober & 30 \\
\hline 11 & November & 20 \\
\hline 12 & Desember & 18 \\
\hline \multicolumn{2}{|r|}{ Total } & 243 \\
\hline
\end{tabular}

Data jumlah mesin setiap work centre dapat dilihat pada tabel 3 berikut ini:

Tabel 3. Data Jumlah Mesin Setiap Work Centre

\begin{tabular}{|c|c|c|}
\hline No & Nama Work Centre & Jumlah Mesin \\
\hline 1 & $\begin{array}{c}\text { Pembuatan Rakitan } \\
\text { Tulangan }\end{array}$ & 3 buah \\
\hline 2 & Penulangan & 2 buah \\
\hline 3 & Pengecoran & 2 buah \\
\hline 4 & Stressing & 2 buah \\
\hline 5 & Spining & 1 buah \\
\hline 6 & Penguapan & buah \\
\hline 7 & $\begin{array}{c}\text { Pengeluaran Produk } \\
\text { dari Cetakan }\end{array}$ & \\
\hline
\end{tabular}

Data Jumlah tenaga kerja setiap work centre dapat dilihat pada tabel 4 berikut ini:

Tabel 4. Data Jumlah Tenaga Kerja Setiap Work Centre

\begin{tabular}{|c|c|c|}
\hline No & Nama Work Centre & Jumlah Tenaga Kerja \\
\hline 1 & $\begin{array}{c}\text { Pembuatan Rakitan } \\
\text { Tulangan }\end{array}$ & orang \\
\hline 2 & Penulangan & orang \\
\hline 3 & Pengecoran & orang \\
\hline 4 & Stressing & 2 orang \\
\hline 5 & Spining & 1 orang \\
\hline 6 & Penguapan & orang \\
\hline 7 & $\begin{array}{c}\text { Pengeluaran Produk } \\
\text { dari Cetakan }\end{array}$ & \\
\hline
\end{tabular}

Waktu siklus adalah waktu yang digunakan untuk menyelesaikan satu unit produk. Dalam pengukuran waktu siklus menggunakan metode stopwatch time study (pengukuran waktu secara langsung) dengan jumlah pengamatan sebanyak 10 kali untuk masing-masing work centre. Hasil pengukuran waktu siklus untuk produk tiang pancang dapat dilihat pada tabel 5 berikut ini:

Tabel 5. Data Waktu Siklus Produk Tiang Pancang 


\begin{tabular}{|c|c|c|c|c|c|c|c|}
\hline No & $\begin{array}{c}\text { WCI } \\
\text { (menit) }\end{array}$ & $\begin{array}{c}\text { WC II } \\
\text { (menit) }\end{array}$ & $\begin{array}{c}\text { WC III } \\
\text { (menit) }\end{array}$ & $\begin{array}{c}\text { WC IV } \\
\text { (menit) }\end{array}$ & $\begin{array}{c}\text { WC V } \\
\text { (menit) }\end{array}$ & $\begin{array}{c}\text { WC VI } \\
\text { (menit) }\end{array}$ & $\begin{array}{c}\text { WC VII } \\
\text { (menit) }\end{array}$ \\
\hline 1 & 01.28 & 01.16 & 03.48 & 01.16 & 03.52 & 30 & 04.16 \\
\hline 2 & 01.30 & 01.22 & 03.36 & 01.20 & 03.55 & 30 & 04.20 \\
\hline 3 & 01.25 & 01.15 & 03.34 & 01.16 & 03.50 & 30 & 04.13 \\
\hline 4 & 01.29 & 01.25 & 03.40 & 01.25 & 03.47 & 30 & 04.16 \\
\hline 5 & 01.27 & 01.17 & 03.47 & 01.15 & 03.52 & 30 & 04.12 \\
\hline 6 & 01.31 & 01.24 & 03.45 & 01.16 & 03.49 & 30 & 04.17 \\
\hline 7 & 01.26 & 01.16 & 03.47 & 01.23 & 03.51 & 30 & 04.15 \\
\hline 8 & 01.25 & 01.23 & 03.35 & 01.20 & 03.47 & 30 & 04.18 \\
\hline 9 & 01.28 & 01.17 & 03.38 & 01.17 & 03.53 & 30 & 04.16 \\
\hline 10 & 01.32 & 01.15 & 03.41 & 01.19 & 03.54 & 30 & 04.19 \\
\hline
\end{tabular}

Waktu set up adalah waktu yang dibutuhkan untuk mengatur ulang mesin. Tidak semua mesin memiliki waktu set up, pada pembuatan produk tiang pancang hanya mesin wire caging dan mesin batching yang memiliki waktu set up. Adapun waktu set up pada mesin produksi dapat dilihat pada tabel 6:

Tabel 6. Data Waktu Set Up Mesin Produksi

\begin{tabular}{|c|l|c|c|}
\hline No & Work Centre & $\begin{array}{c}\text { Waktu } \\
\text { (menit) }\end{array}$ & Waktu (Jam) \\
\hline 1 & Work Centre I & 5.00 & 0.083 \\
\hline 2 & Work Centre II & 2.12 & 0.035 \\
\hline 3 & Work Centre III & 4.02 & 0.067 \\
\hline 4 & Work Centre IV & 1.04 & 0.017 \\
\hline 5 & Work Centre V & 2.30 & 0.038 \\
\hline 6 & Work Centre VI & - & - \\
\hline 7 & Work Centre VII & - & - \\
\hline
\end{tabular}

\section{Pengolahan Data}

\section{Waktu Normal}

Rekapitulasi perhitungan waktu normal produk tiang pancang pada setiap work centre dapa dilihat pada tabel 7 berikut ini:

Tabel 7. Rekapitulasi perhitungan waktu normal

\begin{tabular}{|c|c|c|c|c|}
\hline No & Work Centre & $\begin{array}{c}\text { Waktu } \\
\text { siklus } \\
\text { rata-rata } \\
\text { (menit) }\end{array}$ & $\begin{array}{c}\text { Rating } \\
\text { Factor }\end{array}$ & $\begin{array}{c}\text { Waktu } \\
\text { Normal } \\
\text { (menit) }\end{array}$ \\
\hline 1 & Work Centre I & 01.28 & 1 & 01.28 \\
\hline 2 & Work Centre II & 01.15 & 1 & 01.15 \\
\hline 3 & Work Centre III & 03.41 & 1 & 03.41 \\
\hline 4 & Work Centre IV & 01.19 & 1 & 01.19 \\
\hline 5 & Work Centre V & 03.51 & 1 & 03.51 \\
\hline 6 & Work Centre VI & 60 & 1 & 60 \\
\hline 7 & Work Centre VI & 04.16 & 1 & 04.16 \\
\hline
\end{tabular}

Waktu normal adalah waktu siklus produk setelah mempertimbankan rating factor. Tujuan ditetapkan rating factor adalah menetapkan pekerja dalam kondisi paling normal.

\section{Waktu Baktu}

Setelah dilakukan perhitungan waktu normal untuk masing-masing work centre, kemudian dilakukan perhitungan untuk mencari waktu baku, dimana waktu baku merupakan waktu normal yang telah diberikan allowance.

Setelah dilakukan penilaian allowance untuk masingmasing work centre,selanjutnya dilakukan perhitungan waktu baku. Adapun rekapitulasi waktu baku pada setiap work centre dapat dilihat pada tabel 8 berikut ini:

Tabel 8. Perhitungan Waktu Baku

\begin{tabular}{|c|c|c|c|c|}
\hline No & Work Centre & $\begin{array}{c}\text { Waktu } \\
\text { Normal } \\
\text { (menit) }\end{array}$ & Allowance & $\begin{array}{c}\text { Waktu } \\
\text { Baku } \\
\text { (menit) }\end{array}$ \\
\hline 1 & Work Centre I & 01.28 & $25 \%$ & 1.70 \\
\hline 2 & Work Centre II & 01.15 & $28 \%$ & 1.60 \\
\hline 3 & $\begin{array}{c}\text { Work Centre } \\
\text { III }\end{array}$ & 03.41 & $32 \%$ & 5.00 \\
\hline 4 & $\begin{array}{c}\text { Work Centre } \\
\text { IV }\end{array}$ & 01.19 & $34 \%$ & 1.80 \\
\hline 5 & Work Centre V & 03.51 & $29 \%$ & 4.94 \\
\hline 6 & $\begin{array}{c}\text { Work Centre } \\
\text { VI }\end{array}$ & 30 & $30 \%$ & 42.86 \\
\hline 7 & $\begin{array}{c}\text { Work Centre } \\
\text { VII }\end{array}$ & 04.16 & $33 \%$ & 6.21 \\
\hline
\end{tabular}

\section{Peramalan}

Dari hasil ketiga metode peramalan dengan menggunakan software QM for Windows, maka didapatkan nilai SEE terkecil yaitu metode linear regression. Adapun hasil peramalan dari metode linear regression dapat dilihat pada tabel 9 berikut ini:

Tabel 9. Hasil Peramalan

\begin{tabular}{|c|c|c|}
\hline No & Bulan & Hasil Peramalan \\
\hline 1 & Januari 2020 & 3599 \\
\hline 2 & Februari 2020 & 3608 \\
\hline 3 & Maret 2020 & 3617 \\
\hline 4 & April 2020 & 3626 \\
\hline 5 & Mei 2020 & 3635 \\
\hline 6 & Juni 2020 & 3644 \\
\hline 7 & Juli 2020 2033 \\
\hline 8 & Agustus 2020 & 3662 \\
\hline 9 & September 2020 & 3671 \\
\hline 10 & Oktober 2020 & 3680 \\
\hline 11 & November 2020 & 3689 \\
\hline 12 & Desember 2020 & 3697 \\
\hline
\end{tabular}

\section{Rough Cut Capacity Planning}

1. Kapasitas Dibutuhkan (Capacity Requirement)

Setelah perhitungan peramalan untuk mengetahui jumlah produksi produk tiang pancang selanjutnya akan dilakukan perhitungan kapasitas setiap work centre yang dibutuhkan untuk memproduksi tiang pancang berdasarkan hasil peramalan dan waktu operasi.

Capacity requirement $=\mathrm{a}+(\mathrm{b} \times \mathrm{c})$

$$
\begin{aligned}
& =0.083+(3599 \times 0.03) \\
& =108 \mathrm{Jam}
\end{aligned}
$$

\section{Kapasitas Tersedia (Capacity Available)}

Setelah dilakukan perhitungan kapaitas yang dibutuhkan untuk maisng-maisng work centre 
selanjutnya akan dilakukan perhitungan kapasitas yang tersedia di pabrik.

Capacity Available $=\mathrm{d} \times \mathrm{e} \times \mathrm{f}$

$$
=16 \times 8 \times 4
$$$$
=512 \mathrm{jam}
$$

Rough Cut Capacity Planning berguna untuk membangdingkan kapasitas yang tersedia dipabrik dengan kapasitas yang dibutuhkan secara kasar. Setelah dilakukan perhitungan kapasitas yang dibutuhkan dan kapasitas yang tersedia maka akan didapatkan work centre yang memiliki kekurangan kapasitas. Terdapat empat work centre yang mengalami kekurangan kapasitas yaitu work centre III, V, VI, dan VII. Adapun rekapitulasi perhitungan jumlah kekurangan kapasits pada work centre III, V, VI dan VII dapat dilihat pada tabel berikut ini:

Tabel 10. Rekapitulasi Perhitungan Jumlah Kekurangan Pada Work Centre III, V, VI dan VII

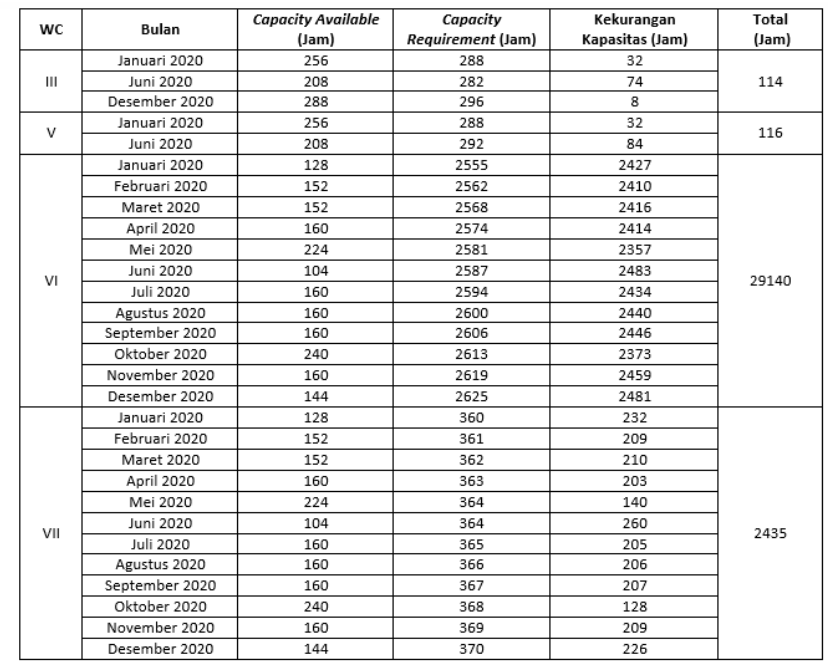

\section{Analisis Permintaan Konsumen dan Kapasitas Produksi}

Berdasarkan hasil perhitungan yang dilakukan dengan menggunakan software QM For Windows, maka didapatkan nilai SEE terkecil yaitu metode linear regression. Pada bulan Januari - Desember 2019 permintaan konsumen sebesar 42489 unit sedangkan pada bulan Januari - Desember 2020 sebesar 43781unit Kekurangan kapasitas yang terjadi disebabkan karena adanya ketidaksesuaian permintaan yang cenderung meningkat dengan keterbatasan kapasitas produksi yang dimiliki. Kekurangan kapasitas yang terjadi pada work centre III, V, VI, VII dapat mengakibatkan ketidakmampuan perusahaan dalam memenuhi permintaan konsumen. Oleh karena itu, kapasitas pada work centre III, V, VI, VII harus direncanakan agar terintegrasi dengan jadwal induk produksi sehingga dapat terpenuhi permintaan konsumen.

\section{Analisis Penyesuaian (Readjusment)}

Kekurangan kapasitas terjadi di work centre III dan V diatas dengan mengusulkan penyesuaian kapasitas. Penyesuaian pada work centre III dilakukan dengan memindahkan beban kerja ke periode yang memiliki kapasitas yang berlebih. Pada work centre III kekurangan kapasitas terjadi pada bulan Januari, Juni dan Desember. Pada bulan Juanuari kapasitas yang kurang adalah 32 jam maka daripada beban kerja dipindahkan ke bulan Februari dan April dikarenakan memilki kapasitas berlebih. Pada bulan Juni kapasitas yang kurang adalah 84 jam maka daripada itu beban kerja dipindahkan ke bulan Mei dikarenakan memiliki kapasitas berlebih dan pada bulan Desember kapasitas yang kurang adalah 8 jam maka daripda itu beban kerja dipindahkan ke bulan November dikarenkan memiliki kapasitas berlebih. Setelah dilakukan penyesuaian (readjustment) maka kapasitas dapat terpenuhi.

Penyesuaian pada work centre $\mathrm{V}$ dilakukan dengan memindahkan beban kerja ke periode yang memiliki kapasitas yang berlebih. Pada work centre $\mathrm{V}$ kekurangan kapasitas terjadi pada bulan Januari dan Juni maka daripada itu beban kerja dipindahkan ke periode yang memiliki kapasitas berlebih. Pada bulan Juanuari kapasitas yang kurang adalah 32 jam maka daripada beban kerja dipindahkan ke bulan Februari dan April dikarenakan memilki kapasitas berlebih. Pada bulan Juni kapasitas yang kurang adalah 84 jam maka daripada itu beban kerja dipindahkan ke bulan Mei dikarenakan memiliki kapasitas berlebih. Setelah dilakukan penyesuaian (readjustment) maka kapasitas dapat terpenuhi.

\section{Analisis Penambahan Jam Kerja Lembur}

Penambahan jam kerja lembur dilakukan karena terjadi kekurangan kapasitas disetiap bulan yaitu dari bulan Januari-Desember 2020 pada work centre VI dan VII. Dikarenakan kapasitas yang dibutuhkan lebih besar dibandingkan dengan kapasitas tersedia pada work centre VI maka penambahan jam kerja lembur adalah 162 jam/bulan. Sedangkan pada work centre VII penambahan jam kerja lembur adalah 14 jam/bulan. Dari hasil perhitungan jam kerja lembur disetiap bulannya pada work centre VI dan VII kapasitas yang kurang dapat terpenuhi.

\section{Kesimpulan}

Berdasarkan penelitian yang telah dilakukan maka diperoleh kesimpulan yaitu, hasil analisis kebutuhan kapasitas dengan menggunakan metode rough cut capacity planning terdapat empat work centre yang mengalami kekurangan kapasitas. Pada work centre III terjadi kekurangan kapasitas sebesar 114 jam dan pada work centre $\mathrm{V}$ terjadi kekurangan kapasitas sebesar 116 jam, langkah yang dilakukan untuk mengatasi kekurangan kapasitas pada work centre III dan V dengan melakukan penyesuain (readjustment) kapasitas yaitu memindahkan beban kerja ke periode yang mengalami kelebihan kapasitas.. Pada work centre VI terjadi kekurangan 
kapasitas disetiap bulannya sebesar 29140 jam dan pada work centre VII terjadi kekurangan kapasitas disetiap bulannya sebesar 2435 jam, langkah yang dilakukan untuk mengatasi kekurangan kapasitas pada work centre VI dan VII dengan melakukan penambahan jam kerja lembur disetiap bulannya. Setelah dilakukan penyesuian (readjustment) dan penambahan jam kerja lembur maka kapasitas untuk setiap work centre terpenuhi.

\section{Daftar Pustaka}

[1]Gaspersz, V. (2004). Production Planning and Inventory Control. Jakarta: PT Gramedia Pustaka Umum.

[2 ]Ginting, R. (2007). Sistem Produksi. Yogyakarta: Graha IImu.

[3 ] Kusuma, H. (2004). Manajemen Produksi. Yogyakarta: Andi.
[4 ] Nurmianto, E. (2008). Ergonomi, Konsep Dasar dan Aplikasinya. Institut Teknologi Sepuluh November.

[5 ]Saebiah, S. (2018). Aplikasi QM for windows. Retrieved March 27, 2019.

[6 ]S.Buffa, E. (1983). Manajemen Produksi/ Operasi Modern. Jakarta: Erlangga.

[7 ] Simulingga, S. (2009). Perencanaan dan Pengendalian Produksi. Yogyakarta: Graha IImu.

[8 ]Sofyan, D. K. (2013). Perencanaan \& Pengendalian Produksi. Yogyakarta: Graha IImu. 